\title{
Methodology and Business Model Analysis with Agile Software Development
}

\section{Marco Antônio Benevides Linhares (IC). \\ Resumo}

The project consists in carrying out a study of the market, business model and methodologies used in a technology-based company associated with the Incubator of Unicamp. The result of the study was applied to professional soccer clubs with the development of an application that uses the iBeacon technology to make sports performance analysis and promote tactical schemes creations for a team, optimizing existing processes in the market at a more affordable cost.

agile development, iBeacon, sports performance.

\section{Introdução}

The international professional soccer, with an estimated audience of 250 million practitioners and an industry valued at US $\$ 500$ billion, is in a constant process of methodological improvement in hiring, training, tactical schemes and analysis of sports performance in order to gain competitive advantage in the markets where they operate.

For the implementation of these goals, the iBeacon, a technology developed by Apple, which uses a Bluetooth 4.0 low-power network, can be used in conjunction with a mobile application to assess technical, physical variables and tactics of players in their respective positions and the whole team.

\section{Resultados e Discussão}

Agile Development promotes a conceptual framework to conduct software engineering projects and the Lean Startup methodology proposes the use of validation and metrics for accelerated growth of a business. Companies associated to Incamp, the Incubator of Technology-Based Companies of Unicamp, use these tools to accelerate their development.

These techniques were used in the creation of an application for soccer club focusing on the sports performance measurement of athletes and the creation of tactical schemes to soccer clubs. Tests were performed with four beacon models and the results are shown in the following table.

Table 1. Battery length in months for different models of beacons using frequencies of $100 \mathrm{~ms}$ and 0dbmw power, generating up to 50 meters of radius coverage.

\begin{tabular}{|c|c|c|c|}
\hline Gimbal & Minew & Estimote & Kontakt.io \\
\hline 0.9 & 2.8 & 4.0 & 4.5 \\
\hline
\end{tabular}
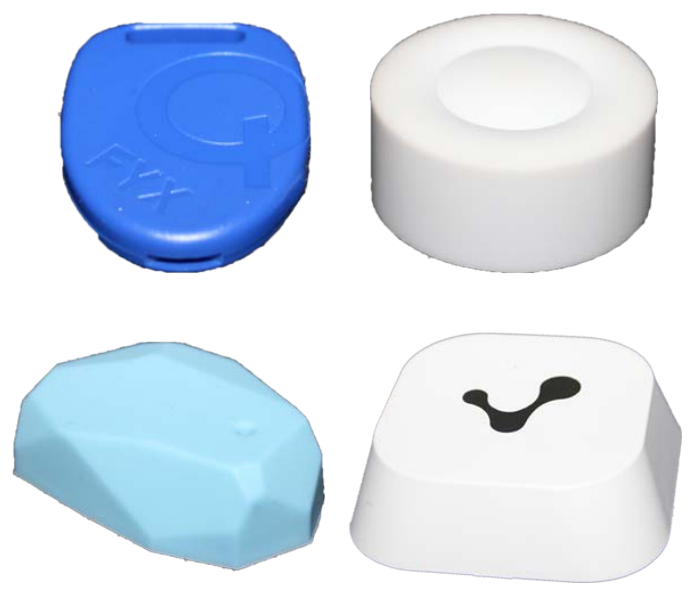

Figure 1. Beacons tested during the development. Models: Gimbal Series 10, Minew MS54V3, Estimote and Kontakt.io, respectively, from left to right and from top to bottom.

\section{Conclusões}

Agile Development using in conjunction with the Lean Startup methodology provides rapid advances in prototyping, validation and creation of a business model for a company in development. These techniques have been successfully applied in creating a commercial product for soccer clubs.

\section{Agradecimentos}

Professor Sérgio Cunha, Geraldo Araujo, Raphael dos Santos and Agency of Innovation from Unicamp for supporting the project since its beginning.

\footnotetext{
${ }^{1}$ OSTERWALDER, A., PIGNEUR, Y., \& CLARK, T. (2010). Business model generation: a handbook for visionaries, game changers, and challengers.

${ }^{2}$ RIES, E. (2011) The Lean Startup: How Today's Entrepreneurs Use Continuous Innovation to Create Radically Successful Businesses. New York: Crown Business..
} 